\title{
Filosofia da práxis e (neo)pragmatismo
}

\author{
Giovanni Semeraro
}

Universidade Federal Fluminense, Faculdade de Educação

\section{Proximidade e contraposição entre filosofia da práxis e pragmatismo}

Em artigo recente publicado pela revista Critica Marxista, da Itália, Chiara Meta (2004) apresenta um estudo em que mostra diversas convergências entre a filosofia da práxis elaborada por Gramsci e o pragmatismo de alguns clássicos americanos, principalmente William James e John Dewey. Ao lembrar que Gramsci considerava $O s$ princípios de psicologia de W. James "o melhor manual de psicologia” (Gramsci, 1996, p. 249), indica que no Caderno 22 há alguns elementos (atos voluntários e involuntários, atividade muscularnervosa etc.) e o próprio conceito de "hábito" derivados do autor norte-americano.

Interessantes são, também, os pontos de contato que a autora procura colocar em evidência entre Gramsci e Dewey, particularmente em relação à pedagogia e à função democratizadora da escola. Ao mostrar que os dois se depararam com os processos de industrialização e massificação de um novo modo de produção e de conhecimento nas primeiras déca- das do século XX, sugere que entre Democracia e educação de Dewey e os Cadernos 12 e 22 de Gramsci há mais "passagens" subterrâneas do que se possa pensar.

Além de outras afinidades, como por exemplo uma certa convergência no entendimento da linguagem, o artigo chega a sugerir que, tal como na filosofia da práxis de Gramsci, os nexos filosofia-senso comum e filosofia-política caracterizam também o próprio pensamento do pragmatismo.

Pelo menos à primeira vista, certamente as sintonias entre filosofia da práxis e pragmatismo não são poucas. Além dos indicados no artigo de Meta (2004), poderíamos assinalar aqui outros possíveis temas que nos Cadernos do cárcere (Quaderni del carcere) de Gramsci (1975, doravante citado pela letra Q) se prestariam para desdobramentos de um estudo paralelo mais amplo com o pragmatismo:

- a concepção de uma filosofia imanente (Q 11, 1438; Q 16, 1226) e histórica (Q 11, 1426), destituída de metafísica (Q 11,1479), de qualquer princípio de autoridade ou de vinculação 
religiosa que fomentem a submissão, a passividade, a alienação e a mistificação;

- o fim da filosofia tradicional essencialista, inatista ou transcendental $(\mathrm{Q} 1,119)$ e a sua construção experimental, pública e discursiva (Q 11, 1449);

- a oposição ao positivismo, a crítica do racionalismo e do idealismo (Q 11,1403-58);

- a superação de dualismos e dicotomias que separam a matéria do espírito, o corpo da mente, o pensamento do ser, o sujeito do objeto, o homem da natureza, a historia da ciência (Q 4, 467; Q 11, 1457);

- o menosprezo pelas abstrações, pelo escolasticismo e os problemas inúteis;

- a ênfase na ação, nas práticas concretas, nos resultados verificáveis coletivamente (Q 10, 1330);

- a valorização da ciência e da experiência, do agir mais do que o contemplar (Q 11,1467);

- a busca do consenso e o reconhecimento do senso comum (Q 11, 1380);

- o caráter histórico, social e superável do conhecimento, que deve ser continuamente verificado, entendido como fruto de construção e não de descoberta, vinculado a justificativas concretas, não a especulações e devaneios ( $\mathrm{Q}$ $1,114)$;

- a construção de uma educação democrática, criativa, elaborada em conjunto, não hierárquica e autoritária (Q 10, 1330).

Essas e outras questões, juntamente com uma certa proximidade de linguagem, têm levado alguns autores a ignorar ou a secundarizar as diferenças e as contraposições entre filosofia da práxis e pragmatismo.

$\mathrm{Na}$ verdade, embora poucas e sumárias, as referências que Gramsci dedica ao pragmatismo norteamericano (mas também italiano: Vailati, Prezzolini, Pareto etc.) são de um autor que valoriza, sim, alguns aspectos, mas que acima de tudo ressalva a insuficiência e as contradições que o caracterizam. Se nos Cadernos, de um lado, anota: "Parece que eles [os pragmatistas] tenham percebido algumas questões reais e as tenham 'descrito' com uma certa exatidão, embora não tenham conseguido impostar os problemas e indicar a solução" (Q 10, 1330), por outro lado, não se deve esquecer que, para Gramsci, o pragmatismo norte-americano está marcado pelo "imediatismo", o "politicismo" e o "ideologismo", que o tornam menos "prático" do que o "filósofo italiano ou alemão" (Q 17, 1925). Na dinâmica do seu "pensamento em movimento" (Baratta, 2004, p. 136s), a pergunta que Gramsci se coloca no primeiro Caderno ["Pode o pensamento moderno difundir-se na América, superando o empirismo-pragmatismo, sem uma fase hegeliana?" (Q 1, 97)], encontra uma resposta no Caderno 17, no qual afirma que, à diferença de "Hegel [que] pode ser considerado como o precursor teórico das revoluções liberais do séc. XIX, os pragmatistas, no máximo, têm ajudado a criar o movimento do Rotary Club ou a justificar todos os movimentos conservadores e reativos" (Q 17, 1926). Mais do que isso, à medida que nos adentramos no estudo dos escritos de Gramsci para compreender o sentido que imprimiu à filosofia da práxis, perde-se de vista a aparente proximidade de alguns pontos com o pragmatismo, diante das fortes diferenças e das contraposições que emergem. Quando, depois, como tentaremos mostrar aqui, se compara a concepção de filosofia da práxis de Gramsci com o neopragmatismo de Rorty, a distância torna-se ainda mais incomensurável e intransponível.

\section{A especificidade da filosofia da práxis}

Deve-se logo observar que quando se fala em "filosofia da práxis" estamos nos referindo ao pensamento mais peculiar engendrado pelo marxismo. Gramsci deixa claro que os "fundadores da filosofia da práxis" são Marx, Engels e Lenin (Q 11, 1436; Q 16, 1856) e, em continuidade com o pensamento por eles inaugurado, procura, principalmente nos Q 10 e 11, aprofundar e conferir novos desdobramentos à filosofia marxista.

Como se sabe, a locução "filosofia da práxis" nos Cadernos do cárcere vai gradativamente substi- 
tuindo a expressão "materialismo histórico", ainda utilizada para designar o marxismo nas três séries de "Anotações de filosofia" dos Q 4, 7 e 8 (Tosel, 1996, p. 49-67; Frosini, 2004, p. 93-111). Com isso, Gramsci procura não apenas se subtrair à censura carcerária, mas, principalmente, visa a contribuir para a consolidação e atualização da nova concepção de mundo, uma tarefa na verdade percebida por Labriola (Q 11, 1507; Q 16, 1855), que ja havia afirmado que "a filosofia da práxis é o coração do materialismo histórico" (1973, p. 702-703).

De modo que, ao se dedicar a aprofundar e destacar os aspectos mais importantes da filosofia da práxis, a preocupação de Gramsci não se limita a redialetizar o pensamento de Marx desfigurado por interpretações marcadas pela metafísica do materialismo mecanicista (Buckarin, Plekanov etc.) ou pelo (neo)idealismo especulativo (Croce, Gentile, Bergson, Sorel etc.). Como resume Martelli:

Em antítese ao "monismo" metafísico idealista (hipóstase do "Espírito") ou positivista-mecanicista (hipóstase da "Matéria"), que de maneira diferente separavam abstratamente o homem da natureza, e também em oposição ao criacionismo gnosiológico subjetivista, Gramsci elabora uma concepção materialista, mas ao mesmo tempo histórica e dialética, da relação homem/natureza, cujo baricentro é constituído pelo conceito de práxis ${ }^{1}$ (1996, p. 41)

Com suas reflexões sobre a filosofia da práxis, de fato Gramsci procura reconduzir o marxismo ao desenho originário das Teses sobre Feuerbach de Marx e à pontualização que Engels faz em Ludwig Feuerbach e a crítica da filosofia clássica alemã. Mas, acima de tudo, para Gramsci, aponta Frosini, "o problema da filosofia da práxis é, ao mesmo tempo, o problema da filosofia depois de Marx, ou seja, do seu estatuto no nosso tempo" (2004, p. 16). Por isso, além do resgate do pensamento originário de Marx, Gramsci

1 Todas as citações de originais em língua estrangeira são traduções livres. procura destacar a especificidade, a originalidade e a maior consistência da filosofia da práxis em relação às outras filosofias. Preocupa-se, então, em colocar em evidência a autonomia, o pensamento novo e independente $(\mathrm{Q} 4,424)$ de um "marxismo [...] que contém em si todos os elementos fundamentais [...] de uma concepção global de mundo [...]"(Q 4, 435), que "renova completamente a maneira de entender a filosofia" (Q 4, 433).

Para essa temática, remetemos a outros estudos (Kosik, 1969; Losurdo, 1990; Semeraro, 2000). Nestas páginas limitamo-nos a dizer, sinteticamente, que para Gramsci filosofia da práxis é a atividade teóricopolítica e histórico-social dos grupos "subalternos" que procuram desenvolver uma visão de mundo global e um programa preciso de ação dentro do contexto em que vivem, com os meios que têm à disposição, visando a construir um projeto hegemônico alternativo de sociedade. Martelli (1996) caracteriza a abrangência da filosofia da práxis em três aspectos inseparáveis: técnico-produtiva, científico-experimental e históricopolítica. Aqui, acrescentaríamos apenas que:

- é práxis técnico-produtiva, porque faz do trabalho a "célula 'histórica' elementar" (Q 4, Q 47, 473), na formação de si mesmos, na mediação ativa que temos com a natureza e com os outros homens (Q 11, 1449);

- é práxis científico-experimental, porque atividade pública de reflexão e pesquisa em vista da construção de um conhecimento e de uma ciência voltados para a humanização do mundo e a expansão da democracia (Semeraro, 2001). Para Gramsci, de fato, “o cientista-experimentador é um trabalhador, não um puro pensador, e o seu pensamento é continuamente controlado pela prática e vice-versa, até se formar a unidade perfeita de teoria e prática" (Q 11, 1449).

- é práxis histórico-política, enquanto atividade que opera a mediação entre "vontade humana (superestrutura) e a estrutura econômica", entre "o Estado e a sociedade civil" (Q 7, 868), entre histórias locais e o contexto global dos 
grupos subalternos, que, ao buscar a libertação, criam um novo modo de agir e de pensar, uma nova visão de mundo, uma filosofia que lança as bases para uma nova civilização.

Assim, para Gramsci o homem não entra em relação com os outros e com o mundo simplesmente pelo fato de ser ele mesmo natureza, mas ativamente, por meio do trabalho, da técnica, da filosofia e da política (Q 10, 1345). Daí porque, além de superar a naturalização do mundo, a cultura de subalternos, o imediatismo e o pragmatismo que afeta o agir das classes trabalhadoras, Gramsci se dedica principalmente a despertar neles a capacidade política que possa levá-los ao autogoverno e à direção de uma nova civilização.

Não há dúvida de que em Gramsci a filosofia da práxis é entendida como uma construção própria das classes subalternas, que se organizam, junto com seus intelectuais, para suplantar e superar a visão restrita e desumanizadora das classes elitizadas. Partindo das contradições (Q 11, 1487) do mundo dirigido e mantido pelos dominantes, a filosofia é da práxis porque os subalternos, com suas práticas políticas, econômicas e culturais, conseguem elaborar uma proposta alternativa, universal e socializadora de mundo, superior à ordem existente, atribuindo-se a tarefa histórica de construir coletivamente, de baixo, uma nova, "total, integral civilização" (Q 11, 1434).

Para Gramsci, só assim os subjugados podem chegar à liberdade, à sua própria identidade e hegemonia. E a conquista desta "unidade na diversidade" acontece no processo político, por meio de uma "luta de hegemonias" (Q 10, 1385), não procurando "intelectualisticamente" (Q 1, 33s) ou "intimisticamente", dentro de si, o conhecimento, os valores e "as razões de vida" (Gramsci, 1996, p. 421, carta de 18/5/1931). Pela filosofia da práxis, na verdade, o homem é visto como "conjunto das relações sociais" (Q 10, 1337), de relações não vagas e abstratas, mas dialeticamente concretas, consideradas dentro de precisas condições de trabalho, de um modo de produção material e simbólico, de divisões de classe, de distribuição da riqueza e do poder no mundo que nos engloba.
Como em Marx não se pode separar o pensar do agir, o mundo material da esfera das idéias, também em Gramsci há uma homologia entre a formação da vontade do indivíduo e a construção de um projeto coletivo de sociedade. Depois de Marx, de fato, chegaram ao fim as concepções de filosofias separadas, especulativa e ideologicamente manipuladas pelas classes dominantes, e inicia-se uma outra fase da humanidade, capaz de vincular organicamente o pensamento à economia e à política, uma vez que a realidade não pode ser pensada e entendida dualística e fragmentariamente. Para Gramsci, "separada da teoria da história e da política, a filosofia acaba se tornando metafísica; por isso, a grande conquista na história do pensamento moderno, operada pela filosofia da práxis, é exatamente a historicização concreta da filosofia e a sua identificação com a história" (Q 11, 1426). Daí porque: "a filosofia deve tornar-se política para ser verdadeira” (Q 11, 1472).

A crítica ideológica da filosofia significa, na prática, a reivindicação da sua ligação com a realidade concreta e histórica. Por isso Gramsci enfatiza a estreita ligação entre filosofia, economia e política, e chega a afirmar que a filosofia da práxis "é uma filosofia que é também uma política e uma política que é também uma filosofia" (Q 16, 1860), e que "a reforma econômica é exatamente o modo concreto por meio do qual se apresenta toda a reforma intelectual e moral" (Q 13, 1561).

A ligação inseparável entre "filosofia, política e economia" $(Q 4,472)$ faz com que a filosofia não se dissolva na abstração ou no intimismo, a política não se torne um cego agir imediatista e pontual, a economia não seja vista como um poder separado, uma fatalidade incontrolável que incumbe sobre os destinos do mundo. Tanto a filosofia quanto a política e a economia, entrelaçadas, para Gramsci formam indivíduos conscientes de sua subjetividade social, fincados no terreno concreto da história e das suas contradições $(\mathrm{Q} 4,471)$ de vida com as quais precisa aprender a interagir para compreender seus mecanismos de poder e se organizar para operar transformações: "O filósofo, de fato, é e não pode não ser o político, quer 
dizer, o homem ativo que modifica o ambiente, entendido este como o conjunto das relações das quais cada um participa" (Q 10, 1345).

Assim, com uma diferença de acento em relação a Marx, que enfatiza mais os processos materiais e econômicos, Gramsci evidencia que a formação da subjetividade dos grupos subalternos não é dada automaticamente, de maneira direta, pela própria condição social ou pela simples inserção no processo de produção material, mas ocorre no processo de construção da hegemonia por meio de um um difícil e complexo trabalho político-cultural capaz de superar a fragmentação, a inércia e a submissão.

Não é por acaso que em Gramsci não é a economia, mas a ideologia, o foco maior da sua atenção. "Para Gramsci, o coração da hegemonia sociopolítica de uma classe dirigente ou de uma classe revolucionária é a capacidade de produzir, ao lado da riqueza material, principalmente uma riqueza teórica, a elaboração de uma visão própria de mundo não subordinada ou colonizada por patrimônios ideológicos alheios. A capacidade de decidir e definir a identidade da própria subjetividade conforme uma filosofia própria, em que não haja mais discrepância entre o plano material e a auto-representação, entre o fazer e o saber dele" (Finelli, 2001, p. 105).

Isso quer dizer que, sem perder de vista esse horizonte teórico-político desenhado por Gramsci no seu tempo, cada grupo social subalterno, em seu lugar e circunstâncias, tem a insubstituível tarefa de elaborar seus horizontes teóricos e construir sua hegemonia. Hoje, por exemplo, a reelaboração da filosofia da práxis não pode deixar de levar em consideração que vivemos na época da globalização dominada pelo "império" norte-americano; que, no pensamento pós-moderno, além de aspectos corrosivos, antidemocráticos e antipopulares, há elementos que podem ser aproveitados no fortalecimento das lutas dos subalternos (Semeraro, 2004); que o conceito de política se ampliou e se complexificou muito; que o trabalho passa por um processo de intelectualização sem precedentes na história da humanidade; que a hegemonia deve ser equacionada com a questão do poder e suas múlti- plas manifestações; que as lutas sociais se modificaram e múltiplos atores se organizam como novos protagonistas na esfera da política; que o socialismo não pode ser dissociado da realização da democracia; que no Brasil e na América Latina não há como pensar a construção de um outro "mundo possível" sem enfrentar e superar as contradições existentes.

\section{A "novidade" do neopragmatismo de R. Rorty}

Se a filosofia da práxis, para além de alguns pontos de aproximação, apresenta profundas divergências teóricas e contrapostos projetos de sociedade em relação ao pragmatismo clássico norte-americano, a distância se torna ainda mais nítida quando se examina o neopragmatismo desenhado por R. Rorty, herdeiro dessa linha de pensamento.

Rorty representa, de fato, o pragmatismo norteamericano na versão pós-moderna mais sofisticada. Seus escritos procuram combinar o pensamento antimetafísico (antiessencialista e anti-representacionista) com um remodelado liberalismo "solidário" e um "vocabulário" inspirado na filosofia da linguagem.

Em Ensaios sobre Heidegger e outros: escritos filosóficos II (1999a, p. 14-15), o próprio Rorty explicita abertamente que o seu projeto filosófico visa a interligar os pragmatistas, particularmente J. Dewey, a Nietzsche, a Heidegger e aos filósofos analíticos norte-americanos Quine, Davidson e Putnam.

Mas, embora mencione constantemente Dewey, na verdade Rorty está sintonizado com a filosofia da vida de Nietzsche e com a crítica à "tradição ontoteológica" de Heidegger, ao mesmo tempo em que retira suas inspirações mais atuais de Donald Davidson, "um filósofo cuja obra parece-me ser a melhor declaração corrente de uma posição pragmatista" (Rorty, 1999a, p. 26). De fato, se por um lado Rorty declara em diversas ocasiões que a sua "admiração por Dewey é quase ilimitada" (Rorty, 1999b, p. 14) e que "o liberalismo naturalista e antiideológico deweano é a mais válida tradição da vida intelectual americana”, por outro lado, está convencido de que "o pragmatismo deveria desenvolver o lado holístico e sincrético para 
poder construir um invólucro melhor para o liberalismo" (Rorty, 1997, p. 93).

Pelo uso que faz dos seus referenciais teóricos e pelas suas próprias declarações, ficam evidentes as posições políticas que Rorty assume em defesa da "utopia liberal" (Rorty, 2001, p. 218) e do modelo norte-americano de sociedade. Um liberalismo que, na esteira das reformadoras teorias de J. Rawls (Rorty, 1997, p. 239ss), Rorty espera ver renascer na América atual, já que "patriotismo, economia solidária, anticomunismo e pragmatismo de Dewey andavam juntos, fácil e naturalmente" (Rorty, 1999b, p. 98). Assim, não há escrito de Rorty em que não apareça, inabalável e indiscutível, metafisicamente presente como "mão invisível", a "crença" de que "sem [...] as instituições da sociedade burguesa liberal os homens teriam mais dificuldade para encontrar a própria salvação pessoal" (Rorty, 2001, p. 103).

Imbuído dessa "missão", Rorty, "anticomunista militante" de esquerda (Rorty, 1999b, p. 94), defende um "liberalismo democrático", uma "social-democracia reformista" que leve à purificação do egoísmo e dos excessos da concorrência para tornar-se sensível ao sofrimento humano e impedir a crueldade (Rorty, 2001, p. 82). Para tanto, sonha com um mundo em que as classes possam trabalhar "cooperativamente" (idem, p. 89); invoca as políticas reformistas de "Dewey e Hook, que lutaram com grande sucesso contra as tentações que o marxismo apresentou aos intelectuais americanos nos anos 30" (Rorty, 1997, p. 107-108); substitui a retórica dos direitos universais com as tradições genuínas do "nosso mundo" norte-americano (Rorty, 1999b, p. 84); contrapõe o conceito de "societas" (sociedade que partilha valores específicos de um preciso grupo social) ao conceito de "universitas" (associação universal dos seres humanos que se reconhecem na mesma natureza humana) (Rorty, 2001, p. 75); está convencido de que não se pode pensar a realização da democracia desvinculada do capitalismo: "democracia participativa e fim do capitalismo são ideais que ninguém é capaz de imaginar sendo realizados" (Rorty, 1999b, p. 139); para o que chama de "esquerda", indica que "deve voltar-se ao trabalho de reforma gradual dentro do quadro de uma economia de mercado" (idem, p. 141), de uma democracia já organizada, na qual "nenhuma 'crítica radical' é requerida, sendo necessário apenas atenção para o detalhe", e na qual "o filósofo [...] é alguém que provoca o confronto entre os bons e os maus aspectos dessa sociedade" (Rorty, 1999a, p. 39, grifo meu). Sem nunca pôr em dúvida a sacralidade do capitalismo, afirma que "deveríamos repudiar a insinuação dos marxistas de que só aqueles que estão convencidos de que o capitalismo deve ser superado podem ser tidos como de esquerda..." (Rorty, 1999b, p. 76). Idealiza, afinal, "uma autoridade global que poderia colocar o capitalismo global a serviço da democracia [...] uma vez que hoje 'socialismo' não significa outra coisa se não 'capitalismo domesticado"” (Rorty \& Vattimo, 2005, p. 82).

Portanto, em contradição com as idéias de diferença, de democracia e de "conversação" aberta de que sua filosofia se diz portadora, Rorty toma partido indiscutível a favor do liberalismo, faz apologia dos seus heróis, valoriza autores de seu interesse e desqualifica outros que não têm "utilidade" para o seu discurso (Rorty, 2001, p. 100), indica com precisão as leituras que servem para uma boa formação e outras que devem ser abandonadas (Rorty, 1999b, p. 93), ergue barreiras contra o marxismo, porque "para nós americanos é importante não permitir que o marxismo influencie a história que contamos sobre nossa própria esquerda" (idem, p. 76), uma vez que "nós americanos não precisamos de Marx para nos mostrar a necessidade de redistribuição [...]" (idem, p. 84). Assim, a aparente liberalidade do seu pensamento e a modéstia de objetivos que a sua filosofia propõe mal escondem a intenção clara de "criar" um modo de pensar mais útil e prático para "refundar" mais eficazmente o liberalismo, modelo inigualável para o mundo, porque livre, sem amarras, sem princípios nem finalidade, cuja missão é "prevenir a miserabilização do proletariado país por país, no espírito pragmático e experimental que Dewey recomendou" (idem, p. 77), e se manter armado, já que "A Guerra Fria [foi] travada [...] para salvar o mundo de um grande perigo" (idem, p. 95). 
Há outros aspectos que chamam a atenção quando nos adentramos na filosofia "solidária" e pós-moderna de Rorty. No mundo da sua encantadora literatura desaparece o "interesse" pelo contexto histórico dentro do qual deve-se entender os fatos, a linguagem, os valores. Em seus escritos não há sinal da divisão social do trabalho e a exploração deste, dos processos históricos, das forças sociais, políticas e econômicas que formam mentalidades e amoldam comportamentos, que levam alguns povos a subjugar outros, que fazem acumular riquezas e concentrar poder no império norte-americano. No lugar de questões pouco pragmáticas como essas, que até suscitam sentimentos de indignação e piedade, Rorty concentra seus esforços sobre o esgotamento da filosofia ocidental tradicional e suas teorias "inúteis" para o nosso tempo.

Partindo da idéia de que estamos em época pósmetafísica e pós-filosófica, Rorty acredita ter havido um deslocamento da subjetividade/identidade fundada sobre a "consciência", para uma concepção que valoriza a completa naturalização das relações entre os homens e o meio. Nessa visão, organismo e ambiente, interno e externo, são considerados holisticamente relacionados única e exclusivamente por causação. $\mathrm{O}$ modelo naturalista, de fato, dispensa a noção de consciência, de sujeito e de processos históricos. Ao abandonar a "metalinguagem" e a introspecção, e ao adotar a observação, o ponto de vista da terceira pessoa analisando expressões lingüísticas, crenças e desejos, Rorty pensa que é possível ser "ontologicamente neutro", "para além do bem e do mal", pelo fato de limitar-se apenas a descrever, sem ideologia, o mundo com seus vários vocabulários, sem privilegiar nenhuma linguagem específica. Na esteira de Nietzsche, portanto, a maior preocupação de Rorty é dissolver a filosofia do sujeito, da consciência, da razão, da verdade, da universalidade, substituindo-a pelo naturalismo, o holismo, a linguagem, a utilidade, a contingência.

Por isso, em conformidade com a "virada lingüística", a filosofia, nas mãos de Rorty, sofre também "a virada da teoria à narratividade" (Rorty, 2001, p. 5). Nesse sentido, o que nos restaria, agora, é aprender a nos "recriar" pela linguagem, a nos redescrever incessantemente por meio de novos vocabulários. O mundo pragmático, natural e palpável de Rorty nos orienta assim a "utilizar" impoliticamente termos e novas metáforas, sem se importar com o contexto histórico e sociopolítico. Rorty acredita, de fato, que

\begin{abstract}
[...] a única coisa que podemos fazer para ampliar o raio dos nossos conhecimentos [...] consiste em ler livros, pois os irônicos passam mais tempo em colocar ordem entre os livros do que entre as pessoas concretas, reais. Eles temem que conhecendo apenas os habitantes do próprio bairro podem acabar presas do vocabulário no qual foram educados e, portanto, procuram conhecer pessoas estranhas (Alcebíades, Julien Sorel), famílias estranhas (os Karamazov, os Causabons) e estranhas comunidades (os Cavalheiros teutônicos, os Nuer, os mandarins da época Sung). (2001, p. 98)
\end{abstract}

Ao se dedicar aos romances e afastar seus olhos das contradições sociopolítico-econômicas existentes no mundo, o neopragmatismo de Rorty quer nos fazer crer que hoje não há mais problemas filosóficos "fundamentais" a serem resolvidos e que a filosofia não passa de uma "crítica literária" (2001, p. 99), de uma "prática discursiva" entre outras que caracterizam a nossa convivência. Por isso, a filosofia deve abandonar sua pretensão de elaborar visões globais de mundo, de fundamentar o conhecimento e de dar sustentação a práticas éticas e políticas, para transformar-se em uma espécie de narrativa, sem nenhuma tentativa de chegar a uma teoria abrangente ou a um projeto de sociedade. Pois, agora, trata-se não de elaborar conceitos, mas de transitar entre vocabulários; não de construir uma epistemologia, mas de dedicar-se aos jogos de linguagem; não de argumentar, mas de justificar para "audiências"; não de auscultar a realidade, mas de "conversar" sobre ela. Qualquer coisa a mais do que isso levaria aos perigos da "sobrefilosoficação". Convencido disso, Rorty pode declarar que "se considerássemos a história humana como história de metáforas sucessivas, para nós o poeta, no sentido geral do artífice de novas palavras, criador de novas linguagens, seria a vanguarda da es- 
pécie" (Rorty, 2001, p. 30). Esse "gênio", sendo o único que "sabe contar a história", tem sua superioridade assegurada em relação "ao resto da raça humana” (idem, p. 39). Em conformidade com o elitismo de Nietzsche e Heidegger, Rorty também acredita que as mudanças no mundo acontecem pelas "revoluções conceituais" (Rorty, 1999a, p. 29), pela introdução de "novas metáforas", pelas idiossincrasias dos grandes pensadores (idem, p. 29), sem relacioná-las às lutas concretas de grupos sociopolíticos, a complexas disputas de contrapostos projetos de sociedade, menos ainda suspeitar que muitas idéias e "metáforas" podem se originar nas ações e nas reflexões de seres humanos comuns.

Com essa reinterpretação da filosofia, o que nos restaria - melhor, aos poetas e pensadores - são as narrativas e o vocabulário, pelos quais "as coisas se tornam mais prontamente manipuláveis", sem esperar alcançar algo, uma vez que "não há nada a ser conhecido sobre coisa alguma a não ser suas relações com outras coisas" (Rorty, 2000, p. 67ss). A meta da investigação e da ciência, de fato, não é a verdade, mas a utilidade. Darwinianamente, é a capacidade cada vez maior de formar os instrumentos necessários para a espécie humana sobreviver. No entendimento pragmatista da investigação, "a linguagem é um conjunto de instrumentos", é um conjunto de "sinais e ruídos que os organismos usam como ferramenta para conseguir o que eles querem" (Rorty, 1999a, p. 17). Sendo assim, a linguagem não deve ser vista como um "quebra-cabeça" para descobrir algum desenho escondido do mundo ou um significado global da existência. De fato, uma vez que a filosofia tradicional faliu com a sua imagem "da mente como sendo um grande espelho" capaz, com seus "métodos puros", de chegar ao conhecimento entendido como "representação" precisa do mundo e capaz de elaborar "uma teoria geral da representação" (Rorty, 1979, p. 6-12), o que nós temos agora é só um "vocabulário contingente" utilizado por uma "comunidade restrita" (idem, p. 365).

Se vivemos em uma sequiência aleatória de acidentes e palavras, não podemos ter a pretensão de compreender e representar a realidade. Então, mais do que uma verdade, é preciso justificar "crenças" para uma audiência com mais facilidade que outras, pois só há vários objetivos locais, práticos, precisos, nenhum objetivo geral porque não há nenhuma justificação última, como não há nenhum centro considerado "consciência" porque não há nenhum "ponto arquimediano" (Rorty, 2000, p. 37-44).

\section{"Praticamente", em que consiste o (neo)pragmatismo?}

A centralidade do "uso de vocabulários contingentes", da "conversa" e da "narrativa" na filosofia de Rorty são tão fortes que chega a operar uma separação entre o mundo da fala e as práticas de vida. Assim, contraditoriamente com seu discurso, mas coerente com o liberalismo que defende, Rorty acaba separando o pensamento do agir político. Refunda, assim, o dualismo que pensava ter superado, a tal ponto de não se importar com o comportamento e as escolhas concretas do filósofo, uma vez que o que vale é o que este pensa e escreve (Rorty, 2000, p. 171). Em um dos exemplos mais ilustrativos dessa atitude, Rorty chega a instruir M. Foucault sobre como deveria ser um verdadeiro filósofo:

Eu estou com vocês enquanto um companheiro cidadão, mas, enquanto filósofo, estou retirado em mim mesmo, perseguindo projetos de auto-invenção que não são do seu interesse. Eu não estou interessado em oferecer fundamentações filosóficas que legitimem o fato de eu estar do seu lado, pois meu projeto filosófico é um projeto privado que não provê nem motivos nem justificações para minhas ações políticas. (Rorty, 1999a, p. 263)

Como Nietzsche, acreditando que a realidade é "um exército móvel de metáforas", e que "não há fatos, mas só interpretações”, o que importa para Rorty é a fabulação e a ironia, não a transformação do mundo.

Contrariamente à filosofia da práxis, portanto, não é a realidade dos grupos humanos concretos, a premência dos seus problemas, a disputa de projetos 
alternativos de sociedade, mas, "hollywoodianamente", as narrativas, os novos vocabulários, as boas intenções de "grandes" autores depositados em livros e seus jogos de linguagem que alimentariam a solidariedade e a criação de novos espaços de convivência. Justamente, Susan Haack (1998) observa que em Rorty as terapias de grupo e as práticas discursivas assumem o lugar dos problemas reais a serem resolvidos. E Habermas, em sua crítica a Rorty, observa que "quando o pensamento filosófico [...] é desvinculado do dever de resolver problemas, e o seu fundamento é transferido para a crítica literária, é-lhe subtraída não só a sua seriedade, mas também a sua produtividade e criatividade" (Habermas, 1990, p. 198).

Rorty, de fato, acredita que simplesmente mudar o nosso modo de falar mudaria "o que queremos fazer e que pensamos de ser” (Rorty, 2001, p. 29). O novo demiurgo, portanto, é a linguagem, melhor, os "novos vocabulários". No lugar do ser, de Deus, da razão, da história, do espírito, do partido, são os fonemas, os "sinais e os ruídos" que chegam a "criar a pessoa humana [...] a fazer aparecer boa ou má, importante ou secundária, útil ou inútil qualquer coisa" (idem, p. 14).

Nesse sentido, a própria sedutora e risonha narrativa de Rorty não é apenas talento pessoal. É a expressão literária de um pensamento que traduz os valores que defende. Seu estilo desinibido, irônico, ousado, seguro, agradável, erudito, está intimamente sintonizado com o método de "bricolagem de discursos", com a liberdade de "construir textos com tramas múltiplas de narrativas provocadoras, contingentes com suas necessidades de cada momento" (Rorty, 2000, p. 11s), como o liberalismo quer.

Com essa "liberdade", Rorty esmera-se em "utilizar" como acha melhor o pensamento de qualquer autor, tentando juntar em seus textos "metáforas" de Hegel e Marx com as de Kierkegaard, Nietzsche, Heidegger e Derrida; afirmações de Dewey e Rawls com proposições de Mill e Habermas (Rorty, 2001, p. $2 \mathrm{ss})$. Sem se importar com o conjunto da obra de um autor e o contexto histórico-político em que escreve, Rorty espera assim, pela via da narrativa e da lingua- gem, construir holisticamente um "belo mosaico" (idem, p. 99). Assim, para fundamentar o neopragmatismo, não apenas Nietzsche e Heidegger nos revelam que as categorias da razão "são meios para o ajuste do mundo a certos fins utilitários", mas também que "só nos tornamos pragmatistas porque Platão e Aristóteles já nos deram um avaliação técnica, instrumental, de para que serve o pensamento" (Rorty, 1999a, p. 48). Com a mesma liberdade pragmática, Rorty chega a afirmar que as Teses contra Feuerbach de Marx formam uma plataforma do pragmatismo (idem, p. 41) e que o método dialético de Hegel é "simplesmente uma técnica literária", que "não tem por objetivo reatar o sujeito com o objeto", que "abandona a idéia de chegar à verdade", que "inaugurou uma tradição da filosofia irônica que continua em Nietzsche, Heidegger e Derrida" (Rorty, 2001, p. 96ss). Por essas e tantas outras afirmações, percebese melhor por que Rorty trava suas lutas em defesa da "contingência": porque só essa, afinal, nos habilita na "capacidade de manipular entes para satisfazermos nossos próprios desejos" (Rorty, 1999a, p. 61). Pela mesma razão, foi observado que quando se procura "desfundamentar" a idéia de natureza humana e de "substância", se objetiva derrubar a idéia de igualdade (Losurdo, 2002, p. 710).

Mas essa habilidade manipulatória nos confirma ainda mais que de "contingente, irônico e solidário", Rorty possui apenas a literatura, porque seus fundamentos a priori e a "crença" em um projeto preciso de sociedade aparecem perfeitamente sólidos e inabaláveis. Pois, quanto mais combate os fundamentos dos... outros, mais 'fundamentalista' torna-se o seu discurso. O livre, neutro, antimetafísico, contingente e criativo neopragmatismo de Rorty, de fato, não consegue se livrar do inquestionável "fundamento" do "american way of life", do seu intocável "ponto arquimediano": o pressuposto "liberal" da existência do indivíduo natural, autônomo, destituído de consciência e interioridade, mas dotado de "crenças" e “desejos", capaz de interação com o universo, mas avesso a buscar visões de mundo que o exponham a se tornar um "ser social" e politicamente organizado. 
Não há surpresa nisso se considerarmos que em Rorty, como em seu mestre Nietzsche, há uma visão naturalista entre os seres humanos e o resto do universo:

Pois, afinal, a autêntica novidade pode muito bem acontecer em um mundo de forças cegas, contingentes, mecânicas. [...] assim, pelo que nós sabemos, ou que nos importa, o uso metafórico da palavra ousia da parte de Aristóteles, de agape da parte de São Paulo, e de gravitas da parte de Newton, foi o resultado da descarga produzida por um raio cósmico na estrutura de alguns neurônios determinantes do cérebro deles. Ou, como é mais plausível, foi o fruto de algum episódio peculiar da infância deles, de uma idéia fixa produzida por algum trauma pessoal. (Rorty, 2001, p. 26)

Essa naturalização serve para Rorty justificar as distâncias que quer tomar das tendenciosas posições político-ideológicas que poderiam pôr em questão a "inocência" do liberalismo com o qual sonha, cuja "substância" permanece dualista porque prega a ironia privada e a solidariedade pública, invoca a piedade diante das crueldades humanas, mas se recusa a descobrir as causas. E não se pode pensar que essas contradições lhe escapam, pois Rorty é um intelectual muito informado para não saber que certas filosofias por ele desqualificadas ameaçam concretamente desmascarar a perversidade do sistema em que vivemos, as desigualdades por ele produzidas, as gigantescas transferências de recursos drenadas dos países pobres para os centros de poder, a militarização que isso comporta, o terrorismo ideológico e financeiro, o aprofundamento da divisão de classe, o fosso que está dividindo tragicamente a humanidade em fronteiras que segregam multidões empobrecidas de grupos humanos encastelados em altos padrões de consumo e de cultura.

Longe dessa realidade "irrelevante", a filosofia de Rorty procura seu brilho na esgrima que trava com o pensamento tradicional europeu, na desconstrução de um passado cuja visão "ocular" e racionalidade impediriam a liberdade da sua própria afirmação, da sua "autocriatividade" e da "redescrição" de si pró- prio. Para ele, de fato, as questões mais importantes concentram-se nos dualismos entre a tradição metafísica e a linguagem atual, a modernidade e a pósmodernidade, a filosofia continental e norte-americana. Não the importa verificar se os dualismos, antes do que na esfera da metafísica e do discurso, nascem, acima de tudo, das relações que se estabelecem entre dominadores e subjugados, entre quem estabelece "valores" conforme seus interesses e os que são empobrecidos. Quando se recusa olhar para essa realidade, de pouco serve evadir-se no mundo das palavras. Agindo assim, contribui-se para a manutenção e a "fundamentação" de outros dualismos igualmente perversos: a separação da filosofia da política, o público do privado, a narrativa das estruturas econômicas, a "societas" de protegidos separada da "universitas" da maioria entregue à "caridade". Por isso, à filosofia de Rorty não interessa a realidade na sua complexa concretude, mas apenas o "jogo de palavras", o construcionismo permanente de acordo com os interesses de um grupo social particular, assumidamente "etnocêntrico" (Rorty, 2001, p. 227), que tudo faz para defender os seus valores que continuam "essencialmente" ocidentais. Ao recusar a análise das contradições e dos processos históricos, a compreensão do mundo em que se debatem outros grupos sociais e diferentes projetos de sociedade, o neopragmatismo de Rorty acaba comprometendo também seus próprios esforços de valorizar o particular e o contingente, porque os volatiliza e os exclui de uma relação maior.

Contrariamente ao que Rorty gosta de apresentar, totalidade, de fato, não significa necessariamente visão totalitária, exaustiva, fechada, única, definitiva, mas, na longa tradição dialética, deve ser entendida como uma compreensão, a mais ampla possível, histórica e superável, que conseguimos alcançar da complexa e contraditória realidade na qual nos movemos interativa e conflitivamente, em busca de conexões entre partes e todo, micro e macro, para que melhor tenhamos condições de transformá-la individual e conjuntamente.

Ao descartar essa leitura dialética - que o tão mencionado Hegel define como "ciência das contra- 
dições e das conexões universais", o neopragmatismo de Rorty, no lugar de construir o concreto ("rica totalidade de múltiplas determinações"), acaba se tornando redutivo, imediatista e abstrato. Sem uma relação maior, até o uso instrumental e operacional do seu vocabulário fica inviabilizado e a "metafísica" da "utilidade" e da "contingência" defendida por Rorty torna-se pobre e sem saída. Transforma-se em uma ilusão pior que a criada por Platão, por ele incansavelmente combatido. A aposta na contingência, no vocabulário, na ironia, mais do que uma ruptura com a filosofia tradicional, na verdade, operam apenas uma inversão, "do ser para os entes", deixando a lógica subjacente substancialmente igual.

A metafísica, de fato, não se combate jogando todas as cartas sobre a aparência e os rodeios das palavras, como haviam já feito os sofistas. K. Otto Apel (1994, p. 183), justamente, tem observado que quando alguém troca alegremente a "episteme" pela "doxa", a "verdade" pelo "útil", acaba renunciando à sua capacidade racional e à visão de conjunto. Quem abraça essa inversão, como Rorty, se recusa a perceber que as armadilhas do poder existem tanto na metafísica tradicional quanto na pressuposição de que tudo se desintegra e volatiliza no ácido corrosivo do relativismo; não se dá conta de que o "poder" do seu neopragmatismo, tão sutil como a "metafísica" das suas "crenças" sem aparente teoria e visão de mundo, afinal de contas acaba colocando-se a serviço de um liberalismo pós-modernizado e de um capitalismo virtual que combatem a política, a formação de subjetividades, do público, dos direitos universais, de outros possíveis projetos de sociedade, porque se recusa a admitir a realidade que produzem: o trágico dualismo na humanidade e a destruição do planeta.

GIOVANNI SEMERARO, doutor pela Faculdade de Educação da Universidade Federal do Rio de Janeiro (UFRJ), é professor adjunto na Faculdade de Educação da Universidade Federal Fluminense (UFF), na qual atua também no Programa de PósGraduação em Educação. É pesquisador do CNPq e coordena o Núcleo de Estudos e Pesquisas em Filosofia Política e Educação (NUFIPE) da UFF. Principais publicações: Gramsci e a socieda- de civil (Petrópolis: Vozes, 2001, 2a edição); O marxismo de Gramsci (In: BOITO JR., Armando et al. (org.). A obra teórica de Marx: atualidade, problemas e interpretações. São Paulo: Xamã, 2000, p. 173-189); Nietzsche e a "vontade de potência" (Revista de Cultura Vozes, Petrópolis, nº 5, v. 94, p. 15-30); Anotações para uma teoria do conhecimento em Gramsci (Revista Brasileira de Educação, Campinas, n 16, jan-abr. 2001, p. 95-104); Tornar-se "dirigente": o projeto de Gramsci no mundo globalizado [In: COUTINHO, Carlos Nelson, TEIXEIRA, Andréa de Paula (orgs.). Ler Gramsci e entender a realidade. Rio de Janeiro: Civilização Brasileira, 2003, p. 261-273]; Linhas de uma filosofia política da educação brasileira (Movimento - Revista da Faculdade de Educação da Universidade Federal Fluminense, n 10 , set. 2004, p. 35-49). Linha de pesquisa atual: o neomarxismo e o neopragmatismo na educação brasileira. E-mail: gsemeraro@globo.com

\section{Referências bibliográficas}

APEL, K. O., (1994). Estudos de moral moderna. Petrópolis: Vozes.

BARATTA, G., (2004). As rosas e os cadernos: o pensamento dialógico de Gramsci. Rio de Janeiro: DP\&A. Tradução de Giovanni Semeraro.

FINELLI, R., (2001). Marx e Gramsci: o confronto de duas antropologias. In: PETRÔNIO, G., MUSITELLI, M. P. (orgs.). Marx e Gramsci: memória e attualità. Roma: Manifestolibri, p. 99-121.

FROSINI, F., (2004). Filosofia della prassi. In: FROSINI, F., LIGUORI, G. Le parole di Gramsci: per un lessico dei Quaderni del carcere. Roma: Carocci.

GRAMSCI, A., (1975). Quaderni del cárcere - v. 4. Torino: Einaudi. Edição crítica de Valentino Gerratana. , (1996). Lettere dal carcere - v. 2. Palermo: Sellerio. Edição A. Santucci.

HAACK, S., (1998). Quanto àquela frase "estudando com espírito literário...”. In: MARGUTTI PINTO, P. R. (org.). Filosofia analítica, pragmatismo e ciência. Belo Horizonte: Ed. UFMG, p. $40-70$

HABERMAS, J., (1990). O discurso filosófico da modernidade. Lisboa: Dom Quixote.

KOSIK, K., (1969). Gramsci e la filosofia della prassi. In: GARIN, E. et al. Gramsci e la cultura contemporane. Roma: Riuniti, p. 45-50. Atti del convegno internazionale di studi gramsciani. 
LABRIOLA, A., (1973). Discorrendo di socialismo e di filosofia. In: LABRIOLA, A. Scritti filosofici e politici. Torino: Einaudi. Edição F. Sbarberi.

LOSURDO, D., (2002). Nietzsche, il ribelle aristocratico: biografia intellettuale e bilancio critico. Torino: Bollati Boringhieri. , (1990). Gramsci, Gentile, Marx e le filosofie della prassi. In: ROSSI, P. et al. Gramsci e il marxismo contemporaneo. Roma: Riuniti, p. 91-114. Atti del convegno internazionale di studi gramsciani.

MARTELLI, M., (1996). Gramsci filosofo della política. Milano: Unicopli.

META, C., (2004). Filosofia della prassi e pragmatismo. Critica Marxista, $\mathrm{n}^{\circ}$ 2/3, p. 41-53.

RORTY, R., (1979). Philosophy and mirror of nature. Princeton: Princeton University Press.

, (1997). Objetivismo, relativismo e verdade: escritos filosóficos I. Rio de Janeiro: Relume Dumará. , (1999a). Ensaios sobre Heidegger e outros: escritos filosóficos II. Rio de Janeiro: Relume Dumará. , (1999b). Para realizar a América: o pensamento de esquerda no século XX na América. Rio de Janeiro: DP\&A. , (2000). Pragmatismo: filosofia da criação e da mudança. Belo Horizonte: Ed. UFMG. Edição C. Magro e A. M. Pereira.

, (2001). La filosofia dopo la filosofia-contingenza, ironia e solidarietà. Roma: Laterza.

RORTY, R., VATTIMO, G., (2005). Il futuro della religione: solidarietà, carità, ironia. Milano: Garzanti. Edição S. Zabala.

SEMERARO, G., (2000). Gramsci e a sociedade civil. $2^{\mathrm{a}}$ ed. Petrópolis: Vozes. , (2001). Anotações para uma teoria do conhecimento em Gramsci. Revista Brasileira de Educação, Campinas, $\mathrm{n}^{\circ} 16$, p. 95-104, jan.-abr.

, (2004). Linhas de uma filosofia política da educação brasileira. Movimento - Revista da Faculdade de Educação da Universidade Federal Fluminense, Niterói, n 10, p. 35-49.

TOSEL, A., (1996). Il lessico della filosofia della prassi di Gramsci. Marxismo Oggi, Milano: Teti Editore, vol. 1, p. 49-67.

Recebido em janeiro de 2005 Aprovado em março de 2005 


\section{Resumos/Abstracts}

\section{Giovanni Semeraro}

\section{Filosofia da práxis e (neo)pragmatismo}

Este artigo apresenta-se como um contraponto às interpretações que evidenciam as convergências entre filosofia da práxis e (neo)pragmatismo. Embora não desconsidere alguns pontos de contato entre as duas concepções, ao resgatar a filosofia da práxis delineada por Gramsci mostra as profundas divergências entre este e o pragmatismo americano. Em seguida, analisa a filosofia de Rorty, que procura construir vinculações entre o pragmatismo, particularmente de Dewey, e o pensamento pós-moderno. São destacadas diversas contradições presentes nos escritos de Rorty, sua funcionalidade ao discurso dominante e o contraposto projeto de sociedade em relação às propostas político-pedagógicas que derivam de uma filosofia da práxis que vem se renovando no Brasil e na América Latina.

Palavras-chave: filosofia da práxis; pragmatismo; Rorty

\section{Philosophy of praxis and (neo)pragmatism}

This article constitutes a counterpoint to those interpretations which provide evidence of the convergence between the philosophy of praxis and (neo)pragmatism. Although it does not ignore some points of contact between the two conceptions, by rescuing the philosophy of praxis outlined by Gramsci, it reveals the profound divergence between this and American pragmatism. It then analyses the philosophy of Rorty which seeks to construct links between pragmatism, especially that of Dewey, and post-modern thought. Diverse contradictions present in the writings of Rorty are emphasised: its utility for the dominant discourse and the opposing project of society with respect to the political pedagogical proposals which derive from the philosophy of praxis and which have undergone processes of renewal in Brazil and Latin America.

Key-words: philosophy of praxis; pragmatism; Rorty 